\title{
PULMONARY FUNCTION IN PULMONARY HYPERTENSION
}

\author{
BY \\ M. B. MCILROY AND G. H. APTHORP \\ From the Institute of Cardiology and the Medical Unit, St. Bartholomew's Hospital
}

Received November 1, 1957

It has been shown by cardiac catheterization that an increased resistance to blood flow through the lungs occurs in four main conditions: (1) congenital heart disease with potential shunt, (2) mitral valve disease or left ventricular failure, (3) chronic lung disease, and (4) primary and thromboembolic pulmonary hypertension. Although the burden of an increased pulmonary vascular resistance falls almost entirely on the circulation, the primary lesion is probably in the lungs. Up to now little has been written about the effect of pulmonary hypertension on pulmonary function and the object of this paper is to report a study of the mechanical properties of the lungs and the diffusing capacity in a group of patients in whom the presence of a raised pulmonary vascular resistance was established by cardiac catheterization.

\section{MATERIAL AND MeTHODS}

Of the 27 patients investigated, 17 had congenital heart disease with a shunt at atrial, ventricular, or ductal level which was usually bi-directional. In no case was the pulmonary blood flow increased, and in all there was clinical and laboratory evidence of an increased pulmonary vascular resistance. In 5 patients mitral valve disease was complicated by pulmonary hypertension with a pulmonary vascular resistance of 10 units $\left(800\right.$ dyne sec. $/ \mathrm{cm}^{-5}$ ) or more. In one case pulmonary hypertension was associated with chronic pulmonary fibrosis, while in the remaining four a diagnosis of primary pulmonary hypertension was made on clinical grounds and confirmed by cardiac catheterization. The relevant physiological findings are given in Table I. In 25 cases pulmonary arterial pressure and pulmonary blood flow were measured; in the other two only right ventricular pressure tracings were obtained, but the clinical findings left no doubt that the pulmonary vascular resistance was raised.

Pulmonary function studies were carried out at rest with the patient sitting in a chair and either during exercise on a motor-driven treadmill or after the patient had walked upstairs. The aspects of pulmonary function studied included the compliance of the lungs, the respiratory resistance, the diffusing capacity of the lungs for carbon monoxide (Dco), the helium mixing curve, and the ventilation equivalent for oxygen $\left(\mathrm{O}_{2} / \mathrm{V}\right)$ during exercise. Compliance in $1 . / \mathrm{cm} . \mathrm{H}_{2} \mathrm{O}$ is a measure of the pressure required to overcome the elastic recoil of the lungs, and respiratory resistance in $\mathrm{cm} . \mathrm{H}_{2} \mathrm{O} / \mathrm{l} . / \mathrm{sec}$. expresses the resistance to air flow in the bronchial tree. The measurement of Dco in $\mathrm{ml} . \mathrm{O}_{2} / \mathrm{min} . / \mathrm{mm} . \mathrm{pO}_{2}$ is an overall measure of the rate of transfer of oxygen into the pulmonary capillary blood: it is influenced by any disturbance of the normal balance between alveolar ventilation and perfusion as well as by abnormality of the alveolar membrane. The helium mixing curve measures the equality of the distribution of ventilation to different parts of the lungs and if it is normal, any reduction in Dco must be due to inequality of perfusion or abnormality of the alveolar membrane. The ventilation equivalent for oxygen in $\mathrm{ml} . \mathrm{O}_{2} / \mathrm{l}$. ventilation expresses the oxygen uptake for a given ventilation and, since oxygen uptake is related to the grade of exercise, the ventilation equivalent measures the efficiency of ventilation.

The compliance and respiratory resistance of the lungs were measured from simultaneous tracings of intra-œsophageal pressure and tidal volume. The pressure in the œsophagus was measured by the method described by Mead et al. (1955). Tidal volume was recorded either by means of a spirometer, the movement of which was transmitted to a potentiometer, or by electrical integration of a pneumotachographic tracing. The compliance of the lungs was measured from the pressure difference at the points of zero air flow and 
TABLE I

Clinical and Physiological Data in 27 Patients with Pulmonary Hypertension

\begin{tabular}{|c|c|c|c|c|c|c|c|c|c|c|c|c|}
\hline \multirow{3}{*}{ 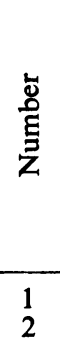 } & \multirow{2}{*}{$\begin{array}{c}\stackrel{\nwarrow}{\varpi} \\
\mathbf{F}\end{array}$} & \multirow[t]{2}{*}{ 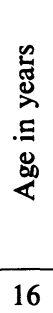 } & \multirow{3}{*}{ 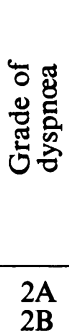 } & \multicolumn{2}{|c|}{ 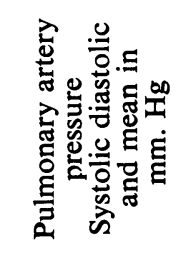 } & \multirow[t]{2}{*}{ 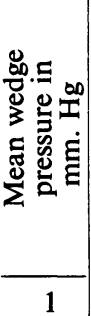 } & \multirow[t]{2}{*}{ 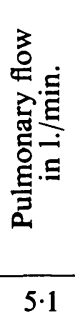 } & \multirow[t]{2}{*}{ 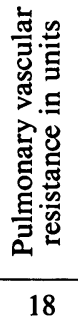 } & \multicolumn{2}{|c|}{ 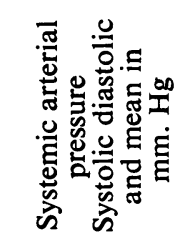 } & \multirow{2}{*}{ 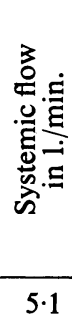 } & $\begin{array}{l}\text { Diagnosis and } \\
\text { remarks }\end{array}$ \\
\hline & & & & $120 / 75$ & 95 & & & & $115 / 75$ & 90 & & A.S.D. \\
\hline & $\mathbf{F}$ & 27 & & $95 / 0^{*}$ & - & - & - & - & & - & - & $\begin{array}{l}\text { A.S.D. (catheter } \\
\text { incomplete) }\end{array}$ \\
\hline 3 & $\mathrm{~F}$ & 30 & 2B & $88 / 50$ & 65 & 5 & $4 \cdot 6$ & 13 & $120 / 85$ & 95 & $2 \cdot 7$ & A.S.D. (L.A. $92 \%$ ) \\
\hline 4 & $\mathbf{F}$ & 31 & $2 B$ & $125 / 75$ & 90 & - & $2 \cdot 1$ & $40 \dagger$ & $115 / 75$ & 85 & $4 \cdot 9$ & A.S.D. \\
\hline $\begin{array}{l}5 \\
6\end{array}$ & $\begin{array}{l}\mathrm{F} \\
\mathrm{F}\end{array}$ & $\begin{array}{l}34 \\
40\end{array}$ & $\begin{array}{l}2 \mathrm{~A} \\
2 \mathrm{~B}\end{array}$ & $\begin{array}{l}90 / 35 \\
75 / 32\end{array}$ & $\begin{array}{l}52 \\
49\end{array}$ & 12 & $\begin{array}{l}2 \cdot 6 \\
2 \cdot 8\end{array}$ & $\begin{array}{l}15 \\
17 \dagger\end{array}$ & $\begin{array}{r}120 / 75 \\
95 / 65\end{array}$ & $\begin{array}{l}96 \\
75\end{array}$ & $\begin{array}{l}2 \cdot 6 \\
3 \cdot 1\end{array}$ & $\begin{array}{l}\text { A.S.D. } \\
\left.\text { A.S.D. (P.V. } 87^{\circ} / 0\right)\end{array}$ \\
\hline 7 & $\mathrm{~F}$ & 54 & 3 & $110 / 5^{*}$ & - & - & $3 \cdot 5$ & & $107 / 55$ & 72 & 3.9 & A.S.D. (P.V. $91 \%)$ \\
\hline 8 & $\mathbf{F}$ & 27 & $2 \mathrm{~A}$ & $75 / 25$ & 40 & 0 & $3 \cdot 0$ & 13 & $110 / 80$ & 85 & $2 \cdot 8$ & A.S.D. ? Ostium \\
\hline 9 & $\mathbf{F}$ & 21 & $2 \mathrm{~A}$ & $120 / 60$ & 80 & 0 & $5 \cdot 3$ & 15 & $120 / 70$ & 85 & $5 \cdot 3$ & V.S.D. \\
\hline 10 & $\mathrm{~F}$ & 26 & $2 \mathrm{~B}$ & $105 / 65$ & 80 & 1 & $3 \cdot 0$ & 26 & $105 / 70$ & 80 & $4 \cdot 1$ & V.S.D. \\
\hline 11 & $\mathbf{F}$ & 40 & 3 & $115 / 50$ & 70 & -4 & $3 \cdot 2$ & 23 & $115 / 60$ & 72 & 3.6 & V.S.D. (P.V. 94\%) \\
\hline 12 & $\mathrm{~F}$ & 57 & 3 & $145 / 55$ & 90 & 0 & $1 \cdot 3$ & 69 & $160 / 100$ & 120 & $2 \cdot 5$ & V.S.D. \\
\hline 13 & $\mathrm{~F}$ & 45 & $2 B$ & $110 / 60$ & 80 & - & $2 \cdot 0$ & $25 \ddagger$ & $110 / 60$ & 80 & $2 \cdot 7$ & M.S. M.I. \\
\hline 14 & $\mathrm{~F}$ & 45 & 3 & $100 / 35$ & 65 & 25 & $1 \cdot 4$ & 24 & $110 / 75$ & 85 & $1 \cdot 7$ & M.S. \\
\hline 15 & $\mathrm{~F}$ & 48 & $2 \mathrm{~B}$ & $90 / 45$ & 60 & 20 & $2 \cdot 2$ & 18 & $130 / 80$ & 95 & $2 \cdot 7$ & M.S \\
\hline 16 & $\mathbf{F}$ & 20 & $2 B$ & $105 / 60$ & 75 & - & $1 \cdot 8$ & $42 \dagger$ & $120 / 80$ & 95 & $2 \cdot 4$ & Idiopathic \\
\hline 17 & $\mathrm{~F}$ & 64 & $2 B$ & $80 / 24$ & 40 & 4 & 1.5 & 24 & $120 / 65$ & 85 & $2 \cdot 4$ & Idiopathic \\
\hline 18 & $F$ & 57 & $2 B$ & $105 / 30$ & 55 & & $3 \cdot 3$ & $15 \dagger$ & $115 / 30$ & 75 & $3 \cdot 3$ & $\begin{array}{l}\text { Cor pulmonale } \\
\text { Pulmonary } \\
\text { fibrosis }\end{array}$ \\
\hline 19 & $\mathbf{M}$ & 45 & 1 & $75 / 25$ & 40 & 1 & $4 \cdot 5$ & 9 & $125 / 65$ & 90 & $5 \cdot 4$ & A.S.D. \\
\hline 20 & $\mathbf{M}$ & 32 & $2 \mathrm{~A}$ & $105 / 60$ & 80 & 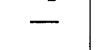 & $2 \cdot 5$ & $32 \uparrow$ & $105 / 60$ & 80 & $3 \cdot 0$ & A.S.D. ? Ostium \\
\hline 21 & $\mathbf{M}$ & 36 & $2 \mathrm{~A}$ & $120 / 60$ & 80 & - & 3.0 & $26 \dagger$ & $120 / 60$ & 80 & $6 \cdot 0$ & V.S.D.+P.D.A. \\
\hline 22 & $\mathbf{M}$ & 43 & $2 B$ & $115 / 65$ & 80 & & $2 \cdot 5$ & $32 \dagger$ & $115 / 65$ & 80 & $4 \cdot 5$ & P.D.A. Bron- \\
\hline 23 & $\mathbf{M}$ & 46 & 2B & $125 / 90$ & 105 & 8 & 3.7 & 26 & $125 / 75$ & 95 & $4 \cdot 1$ & P.D.A \\
\hline 24 & $\mathbf{M}$ & 26 & $2 \mathrm{~A}$ & $110 / 70$ & 80 & 30 & $3 \cdot 3$ & 15 & $90 / 65$ & 75 & $4 \cdot 5$ & M.S. \\
\hline 25 & $\mathbf{M}$ & 39 & $2 \mathrm{~A}$ & $70 / 35$ & 55 & 18 & 3.6 & 10 & $100 / 65$ & 75 & $4 \cdot 0$ & M.I. M.S. \\
\hline 26 & $\mathbf{M}$ & 23 & 1 & $65 / 25$ & 45 & - & $4 \cdot 4$ & $10^{\dagger}$ & $125 / 75$ & 90 & $4 \cdot 8$ & Idiopathic \\
\hline 27 & $\mathbf{M}$ & 46 & $2 \mathrm{~B}$ & $120 / 75$ & 90 & - & $3 \cdot 4$ & $26 \dagger$ & & & - & Idiopathic \\
\hline
\end{tabular}

* Right ventricular pressure. $\quad \dagger$ Assuming wedge pressure zero. $\quad \ddagger$ Assuming wedge pressure 30 .

the tidal volume. The respiratory resistance during inspiration was measured from the non-elastic pressure difference at the mid-point of inspiration and the rate of air flow at the same instant. Both values were expressed as the average for five breaths.

In 11 patients the diffusing capacity of the lungs for carbon monoxide (Dco) was measured by the method described by Bates et al. (1955). In these patients the lung volume (F.R.C.) and "mixing efficiency" were measured using the closed circuit helium method (Bates and Christie, 1950). In a number of patients, the oxygen saturation was measured with an ear oximeter at rest and after exercise. The accuracy of the instrument was checked by comparing oximetric readings with simultaneous arterial samples analysed by Haldane's method. A graph of the oximetric reading plotted against the oxygen saturation of arterial samples is shown in Fig. 1. (p. 400).

\section{RESULTS}

The values for lung compliance and inspiratory resistance at rest and after exercise are shown in Table II, together with the oxygen saturation measured with the oximeter. Although there was 
TABLE II

The Mechanical Properties of the Lungs in 27 Patients with Pulmonary Hypertension

\begin{tabular}{|c|c|c|c|c|c|c|c|c|c|c|}
\hline \multicolumn{6}{|c|}{ Rest } & \multicolumn{5}{|c|}{ Exercise } \\
\hline 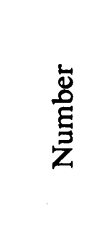 & 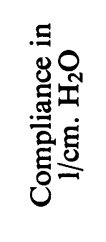 & 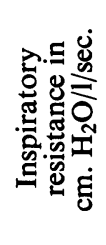 & 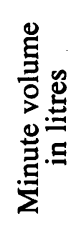 & 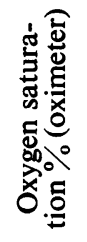 & 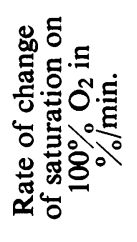 & 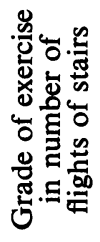 & 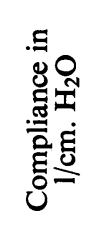 & 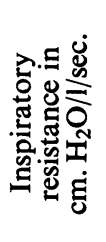 & 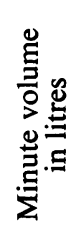 & 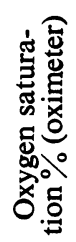 \\
\hline $\begin{array}{r}1 \\
2 \\
3 \\
4 \\
5 \\
6 \\
7 \\
8 \\
9 \\
10 \\
11 \\
12 \\
13 \\
14 \\
15 \\
16 \\
17 \\
18\end{array}$ & $\begin{array}{l}0.184 \\
0.069 \\
0.076 \\
0.139 \\
0.047 \\
0.108 \\
0.256 \\
0.155 \\
0.088 \\
0.141 \\
0.114 \\
0.077 \\
0.022 \\
0.054 \\
0.162 \\
0.160 \\
0.085 \\
0.051\end{array}$ & $\begin{array}{r}2.7 \\
4.5 \\
0.7 \\
3.4 \\
9.1 \\
2.2 \\
5.8 \\
5.7 \\
4.9 \\
5.6 \\
2.4 \\
4.8 \\
10.0 \\
6.9 \\
1.0 \\
9.7 \\
14.0\end{array}$ & $\begin{array}{r}34 \cdot 0 \\
9.7 \\
19.0 \\
13.1 \\
13.1 \\
9.8 \\
11.9 \\
9.6 \\
11 \cdot 1 \\
10.8 \\
16.4 \\
8.6 \\
5.7 \\
9.0 \\
6.1 \\
17.9 \\
9.7 \\
11.2\end{array}$ & $\begin{array}{l}91 \\
85 \\
95 \\
82 \\
92 \\
89 \\
84 \\
93 \\
87 \\
90 \\
90 \\
85 \\
86 \\
87 \\
87 \\
92 \\
87\end{array}$ & $\begin{array}{c}\overline{4 \cdot 3} \\
\overline{3 \cdot 5} \\
\overline{4 \cdot 0} \\
27 \cdot 0 \\
\overline{-} \\
\overline{-} \\
\overline{3} \cdot 8 \\
1 \cdot 4 \\
20 \cdot 0 \\
\overline{-} \\
\overline{14 \cdot 6}\end{array}$ & $\begin{array}{r}3 \\
<1 \\
1 \\
1 \\
4 \\
<1 \\
<1 \\
2 \\
2 \\
2 \\
<1 \\
<1 \\
<1 \\
2 \\
2 \\
2 \\
1\end{array}$ & $\begin{array}{l}0.105 \\
0.073 \\
0.074 \\
0.076 \\
0.133 \\
0.134 \\
0.214 \\
0.178 \\
0.097 \\
0.096 \\
-\overline{0} \\
0.062 \\
0.044 \\
0.097 \\
0.057 \\
0.095 \\
0.076 \\
0.051\end{array}$ & 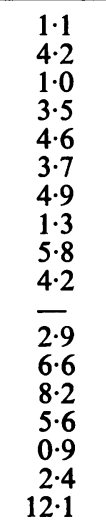 & $\begin{array}{r}51 \cdot 3 \\
22.7 \\
27.2 \\
13.6 \\
30.0 \\
36.6 \\
20.7 \\
33.5 \\
17.0 \\
18.1 \\
-\overline{14.9} \\
8.5 \\
12.3 \\
11.1 \\
43.8 \\
13.4 \\
12.2\end{array}$ & $\begin{array}{l}\frac{80}{95} \\
82 \\
\overline{-} \\
\overline{70} \\
80 \\
\frac{75}{7} \\
\overline{88} \\
\frac{87}{87} \\
\frac{81}{81}\end{array}$ \\
\hline $\begin{array}{l}\text { Mean } \\
\text { Normal } \\
\text { Range }\end{array}$ & $\begin{array}{c}0.114 \\
0.13 \\
0.09- \\
0.18\end{array}$ & $\begin{array}{c}5.5 \\
2.8 \\
1.5- \\
4.8\end{array}$ & $\bar{z}$ & $\begin{array}{l}\bar{z} \\
\bar{z}\end{array}$ & $\begin{array}{l}= \\
\bar{z}\end{array}$ & $\begin{array}{l}\overline{-} \\
\overline{-}\end{array}$ & $\begin{array}{c}0.098 \\
0 \cdot 13 \\
0 \cdot 09- \\
0 \cdot 18\end{array}$ & $\begin{array}{c}4 \cdot 3 \\
2 \cdot 3 \\
2 \cdot 0- \\
3 \cdot 0\end{array}$ & $\begin{array}{l}\bar{z} \\
\bar{z}\end{array}$ & $\begin{array}{l}E \\
z\end{array}$ \\
\hline $\begin{array}{l}19 \\
20 \\
21 \\
22 \\
23 \\
24 \\
25 \\
26 \\
27\end{array}$ & $\begin{array}{l}0 \cdot 115 \\
0.097 \\
0 \cdot 107 \\
0.034 \\
0 \cdot 217 \\
0.081 \\
0.092 \\
0 \cdot 173 \\
0 \cdot 118\end{array}$ & $\begin{array}{r}2 \cdot 2 \\
3 \cdot 8 \\
4 \cdot 2 \\
13 \cdot 7 \\
3 \cdot 2 \\
5 \cdot 1 \\
2 \cdot 3 \\
1 \cdot 0 \\
4 \cdot 3\end{array}$ & $\begin{array}{r}16 \cdot 1 \\
6 \cdot 7 \\
12 \cdot 1 \\
5 \cdot 5 \\
20 \cdot 3 \\
27 \cdot 9 \\
17 \cdot 0 \\
11 \cdot 1 \\
15 \cdot 8\end{array}$ & $\begin{array}{l}87 \\
75 \\
80 \\
96 \\
89 \\
90 \\
90 \\
95\end{array}$ & $\begin{array}{l}3.0 \\
1.7 \\
3.6 \\
= \\
\overline{7.5} \\
= \\
=\end{array}$ & $\begin{array}{l}4 \\
2 \\
4 \\
3 \\
2 \\
2 \\
4 \\
2\end{array}$ & $\begin{array}{l}0.127 \\
0.128 \\
0.125 \\
0.036 \\
-\overline{0} \\
0.072 \\
0.077 \\
0.086 \\
0.128\end{array}$ & $\begin{array}{l}1 \cdot 5 \\
2 \cdot 1 \\
2 \cdot 3 \\
7 \cdot 9 \\
4 \cdot 5 \\
4 \cdot 3 \\
2 \cdot 1 \\
3 \cdot 7\end{array}$ & $\begin{array}{c}38.1 \\
20.7 \\
33.0 \\
10 \cdot 3 \\
26.5 \\
25.0 \\
16.6 \\
29.6\end{array}$ & $\begin{array}{l}- \\
76 \\
93 \\
87 \\
89 \\
90 \\
90\end{array}$ \\
\hline $\begin{array}{l}\text { Mean } \\
\text { Normal }\end{array}$ & $\begin{array}{l}0.115 \\
0 \cdot 19\end{array}$ & $\begin{array}{l}4 \cdot 4 \\
2 \cdot 0\end{array}$ & 二 & - & - & - & $\begin{array}{l}0.097 \\
0.22\end{array}$ & $\begin{array}{l}3.6 \\
1.4\end{array}$ & - & 二 \\
\hline Range & $\begin{array}{l}0.14 \\
0.33\end{array}$ & $\begin{array}{r}0.7- \\
3.5\end{array}$ & - & 二 & 二 & - & $\begin{array}{c}0.12- \\
0.39\end{array}$ & $\begin{array}{r}0 \cdot 6- \\
2 \cdot 2\end{array}$ & 二 & 二 \\
\hline
\end{tabular}

considerable variation from patient to patient, the values for compliance tended to be less, and for inspiratory resistance greater than normal. As would be expected, lung compliance was reduced in the patients with mitral valve disease (Marshall et al., 1954; Hayward and Knott, 1955), and also in the patient with pulmonary fibrosis (Case 18) in whom the inspiratory resistance was also raised. In two patients with congenital heart disease, in whom there was a history of associated lung disease (Cases 7 and 22), the mechanical properties of the lungs were also grossly abnormal. In Case 7, with a long history of asthma, there was a high compliance and a high inspiratory resistance, while in Case 22 with a long history of winter bronchitis, the compliance was greatly reduced and the inspiratory resistance high. Further evidence of associated lung disease was obtained 
from the measurement of the rate of change of oxygen saturation when the patient breathed 100 per cent oxygen. In Cases 7 and 18 the rate of change of saturation was 27 per cent and 15 per cent per minute, indicating that the reduction in arterial saturation was due to impaired diffusion in the lungs rather than to a right-to-left shunt: this will be referred to later when the diffusing capacity is considered. The third patient, in whom the arterial oxygen saturation changed rapidly with 100 per cent oxygen (Case 14), had mitral stenosis, and it is presumed that diffusion in the lungs was impaired in this patient although the diffusing capacity was not measured.

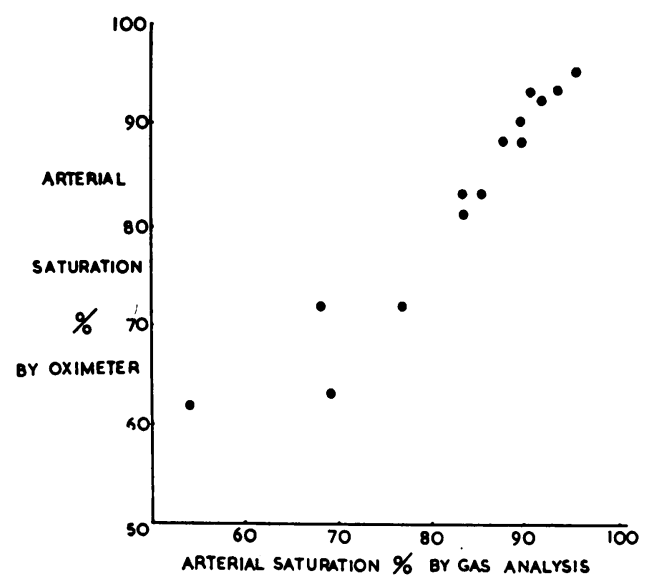

FIG. 1.-Comparison of oxygen saturation of arterial samples with oximeter reading in 13 patients.

The values for lung volume, mixing efficiency, and Dco at rest and during exercise are shown in Table III. The lung volumes were within normal limits and mixing was normal in all except the two patients with associated lung disease (Cases 7 and 18). The values for the diffusing capacity were generally less than normal and, as the values obtained in normal subjects vary with lung volume, the results have been shown in Fig. 2 plotted against the lung volume (F.R.C.). The normal range is derived from the results using this method in young normal subjects (Bates $e t$ al., 1955). It will be seen that Cases 7 and 18 with associated lung disease showed lower values than the rest of the group, confirming the suggestion, made from the measurement of the rate of change of arterial saturation on 100 per cent oxygen, that diffusion was impaired in these two patients. In the other 9 patients the diffusing capacity was lower than expected on the basis of lung volume and did not increase normally on effort. In only one (Case 1), the youngest patient with congenital heart disease studied, was the Dco within normal limits.

The ventilation equivalent for oxygen $\left(\mathrm{O}_{2} / \mathrm{V}\right)$ in $\mathrm{ml} . \mathrm{O}_{2} /$ litre ventilation was measured in 9 patients during exercise and found to be low, indicating a greater ventilation than normal for a given oxygen consumption. In the patients in whom oxygen consumption was not measured, a lowered ventilation equivalent could only be inferred from the high levels of ventilation required for relatively mild exercise. In Case 26, a young man in whom the diagnosis of primary pulmonary hypertension was made following the discovery of a dilated pulmonary artery on mass radiography, the ventilation equivalent was normal. His oxygen consumption on moderately severe exercise was $1550 \mathrm{ml} . / \mathrm{min}$. with a ventilation equivalent of $43 \mathrm{ml} . \mathrm{O}_{2} / 1$. ventilation.

\section{Discussion}

These results indicate that the disturbance of pulmonary function in patients with pulmonary hypertension varies considerably. In deciding how much of the abnormality is due to pulmonary hypertension and how much to associated conditions, it is important to consider the results in those patients in whom there was no associated lung disease and no mitral valve disease, two con- 
TABLE III

The Diffusing Capacity for Carbon Monoxide in 11 Patients with Pulmonary Hypertension

\begin{tabular}{|c|c|c|c|c|c|c|c|c|c|}
\hline \multirow[b]{2}{*}{ 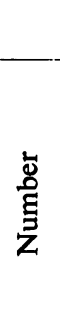 } & \multirow[b]{2}{*}{ 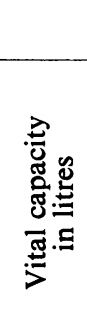 } & \multirow[b]{2}{*}{ 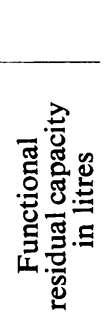 } & \multirow[b]{2}{*}{ 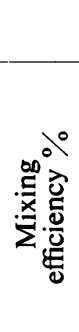 } & \multirow[b]{2}{*}{ 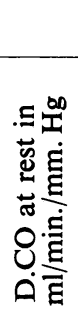 } & \multicolumn{5}{|c|}{ Exercise } \\
\hline & & & & & 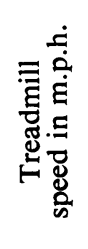 & 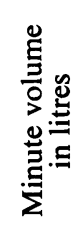 & 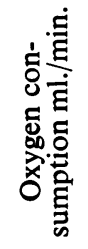 & 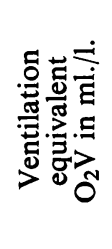 & 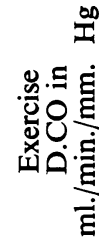 \\
\hline $\begin{array}{r}1 \\
2 \\
3 \\
4 \\
5 \\
7 \\
8 \\
16 \\
18 \\
21 \\
23\end{array}$ & $\begin{array}{l}2.57 \\
1.65 \\
2.16 \\
2.47 \\
2.77 \\
2.04 \\
3.29 \\
2.03 \\
1.50 \\
4.27 \\
3.44\end{array}$ & $\begin{array}{l}2 \cdot 29 \\
2 \cdot 11 \\
2 \cdot 2 \\
3 \cdot 34 \\
2 \cdot 7 \\
3.03 \\
3 \cdot 77 \\
2 \cdot 47 \\
3 \cdot 29 \\
3 \cdot 28 \\
5 \cdot 31\end{array}$ & $\begin{array}{r}71 \\
66 \\
58 \\
102 \\
89 \\
45 \\
80 \\
68 \\
31 \\
78 \\
83\end{array}$ & $\begin{array}{r}15.0 \\
6.4 \\
10.0 \\
9.6 \\
11.2 \\
7.9 \\
12.8 \\
10.0 \\
4.5 \\
17.1 \\
12.4\end{array}$ & $\begin{array}{l}\frac{3}{4} \\
\frac{3}{4} \\
\frac{3}{4} \\
\frac{1}{4} \\
\frac{2}{11} \\
1 \frac{1}{4} \\
1 \frac{1}{2} \\
1 \\
\frac{3}{4} \\
\frac{1}{2}\end{array}$ & $\begin{array}{c}29 \cdot 1 \\
14 \cdot 7 \\
19 \cdot 6 \\
23 \cdot 1 \\
22 \cdot 3 \\
-30 \cdot 3 \\
31 \cdot 2 \\
12.5 \\
22 \cdot 3 \\
20 \cdot 4\end{array}$ & $\begin{array}{l}737 \\
350 \\
510 \\
395 \\
652 \\
\overline{571} \\
549 \\
280 \\
665 \\
770\end{array}$ & $\begin{array}{l}25 \\
24 \\
26 \\
17 \\
29 \\
\frac{19}{19} \\
18 \\
22 \\
30 \\
38\end{array}$ & $\begin{array}{r}20.0 \\
7.6 \\
15.4 \\
13.3 \\
11.4 \\
\overline{16.0} \\
14.8 \\
7.5 \\
19.1 \\
21.0\end{array}$ \\
\hline
\end{tabular}

ditions that are known to affect the mechanical properties of the lungs. The general picture that emerges when such cases are excluded is that pulmonary hypertension is associated with a normal or reduced compliance of the lungs, a normal or slightly raised inspiratory resistance, and a low diffusing capacity which does not increase normally on exercise. That these changes are not the direct result of a raised pulmonary vascular resistance is shown in Case 26, in which pulmonary function was normal in the presence of a pulmonary vascular resistance of 10 units (800 dyne sec. $/ \mathrm{cm} .^{-5}$ ). Any attempt to explain the variable impairment in pulmonary function found in patients with pulmonary hypertension must be speculative, but it seems possible that pulmonary vascular disease with local thrombosis or embolism in different parts of the lungs could produce changes that would vary from patient to patient. If this were the case, the impairment of pulmonary function might well depend on the duration of the pulmonary hypertension. Such a concept is supported by the fact that among the patients with congenital heart disease, the disturbance of

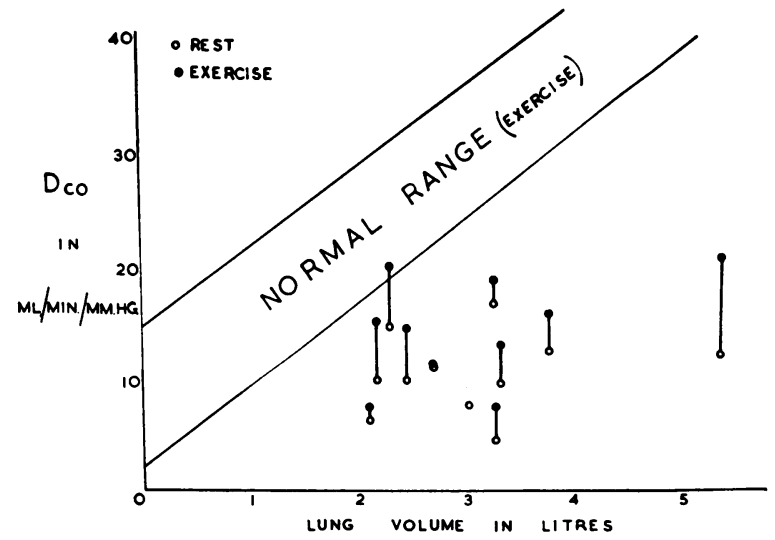

FIG. 2.-The relationship between the diffusing capacity for carbon monoxide and lung volume in 11 patients with pulmonary hypertension. 
pulmonary function was least in the youngest patient (Case 1), and also that, in Case 26, in which primary pulmonary hypertension was diagnosed in a pre-symptomatic stage, pulmonary function was normal. The exact mechanism by which thrombosis or embolism of the pulmonary arterial tree could lead to a reduction in lung compliance and an increase in respiratory resistance is not clear. It has, however, been shown by Doyle et al. (1957) that the pulmonary vascular bed is reduced in patients with pulmonary hypertension and congenital heart disease, and such changes could well account for the reduction in diffusing capacity by reducing the surface area available for gas exchange. It would not then be necessary to postulate any abnormality of the alveolar membrane in such patients. In this connection it should be stressed that the measurement of the diffusing capacity with carbon monoxide measures the overall process of diffusion and is influenced by inequality of ventilation, increased dead space effect, and venous admixture, as well as by any abnormality of the pulmonary membrane itself.

As has been shown, hyperventilation was common in the patients with pulmonary hypertension studied. In those patients with congenital heart disease and a right-to-left shunt, in whom the arterial saturation fell on exercise, hyperventilation would be expected to occur as a result of the fall in arterial oxygen tension and rise in arterial $\mathrm{pCO}_{2}$ associated with increased shunting of venous blood into the systemic circulation on exercise. Some other factor must be invoked to explain the hyperventilation seen in patients with no shunt. The clearest example of this was seen in Case 16, a girl with primary pulmonary hypertension in whom the ventilation equivalent was $18 \mathrm{ml} . \mathrm{O}_{2} / \mathrm{l}$. This hyperventilation was not abolished by oxygen and the stimulus for it is unknown. That it is not directly related to the increased pulmonary vascular resistance is shown by the findings in Case 26 in which a raised pulmonary vascular resistance due to primary pulmonary hypertension was associated with a normal ventilation equivalent. Further work is needed to explain the nature of the ventilatory stimulus in such patients and to explore the suggestion that it may be related to limitation of the cardiac output.

Dyspnœa was the symptom that limited exercise performance in all the patients studied, and it appears that several factors may be responsible for this. Firstly, impairment of the mechanical properties of the lungs must result in an increase in the oxygen cost of breathing; secondly, hyperventilation due either to arterial oxygen unsaturation on effort or to some unknown stimulus must increase the ventilatory requirements for a given grade of exercise; thirdly, the restricted blood flow through the lungs on exercise must limit transport of oxygen to the tissues.

\section{SUMmary}

The mechanical properties and diffusing capacity of the lungs have been measured at rest and on exercise in patients with pulmonary hypertension.

There was no direct relationship between the level of the pulmonary vascular resistance and the degree of disturbance of pulmonary function, which ranged from zero to considerable. In general, patients with pulmonary hypertension showed a variable reduction in lung compliance, diffusing capacity, and ventilation equivalent, and a slight increase in inspiratory resistance.

It is suggested that while pulmonary hypertension per se has no effect on pulmonary function, changes in lung compliance, resistance, and diffusing capacity may result from associated lung disease, mitral valve disease, or the effects of thrombosis or embolism of the pulmonary arterial bed.

We wish to thank the physicians of the National Heart Hospital for allowing us to study their patients.

\section{REFERENCES}

Bates, D. V., Boucot, N., and Dormer, A. E. (1955). J. Physiol., 129, 237.

and Christie, R. V. (1950). Clin. Sci., 9, 17.

Doyle, A. E., Goodwin, J. F., Harrison, C. V., and Steiner, R. E. (1957). Brit. Heart J., $19,353$.

Hayward, G. W., and Knott, J. M. S. (1955). Brit. Heart J., 17, 303.

Marshall, R., McIlroy, M. B., and Christie, R. V. (1954). Clin. Sci., 13, 137.

Mead, J., Mcllroy, M. B., Selverstone, N. J., and Kriete, B. C. (1955). J. app. Physiol., 7, 491. 